\title{
Germline $B R C A$, chemotherapy response scores, and survival in the neoadjuvant treatment of ovarian cancer
}

\author{
Yong Jae Lee ${ }^{1}$, Hyun-Soo Kim², John Hoon Rim³ ${ }^{3}$ Jung-Yun Lee ${ }^{1 *}$, Eun Ji Nam¹, Sang Wun Kim',
} Sunghoon $\mathrm{Kim}^{1}$ and Young Tae Kim ${ }^{1}$

\begin{abstract}
Background: To analyze the effects of BRCA1/2 mutations on chemotherapy response scores (CRS) and survival in a cohort of patients with advanced-stage ovarian cancer who were treated with neoadjuvant chemotherapy (NAC) followed by interval debulking surgery (IDS).

Methods: We retrospectively reviewed the medical records of 169 high-grade serous ovarian cancer patients who underwent a germline BRCA1/2 test and received three cycles of NAC at the Yonsei Cancer Center from 2006 to 2018. Chemotherapy response scores were compared in patients with and without BRCA1/2 mutations. The effects of BRCA1/2 mutations and CRS on survival were evaluated.

Results: BRCA1/2 mutations were detected in 47 (28.1\%) of the 169 patients. Overall, 16 (34.0\%) patients with BRCA1/2 mutations had a CRS 3 to chemotherapy compared to scores of 43 in patients (35.2\%) without a mutation. Response scores of 3 in patients with BRCA1/2 mutations were not significantly associated with either improved progression-free survival (PFS) $(P=0.949)$ or overall survival $(O S)(P=0.168)$. However, $C R S 3$ in patients without BRCA mutations was significantly associated with both improved PFS $(P=0.030)$ and OS $(P=0.039)$. In patients with CRS1/2, carriers of BRCA1/2 mutations had better PFS $(P=0.0344)$ and OS $(P=0.043)$ than wild-type $B R C A$ genotype patients.

Conclusion: In ovarian cancer patients treated with NAC, CRS did not predict survival for BRCA 1/2 mutation carriers but did for BRCA wild-type patients.
\end{abstract}

Keywords: Ovarian cancer, Neoadjuvant chemotherapy, Germline BRCA, Chemotherapy response scores

\section{Background}

Primary cytoreductive surgery followed by platinumbased doublet chemotherapy has been considered standard treatment for advanced-stage ovarian cancer. However, several randomized clinical trials showed that their survival outcomes and postoperative morbidity and

\footnotetext{
* Correspondence: yodrum682@gmail.com

${ }^{1}$ Department of Obstetrics and Gynecology, Institute of Women's Life Medical Science, Yonsei University College of Medicine, 50-1 Yonsei-ro, Seodaemun-gu, 03722 Seoul, Republic of Korea

Full list of author information is available at the end of the article
}

mortality after neoadjuvant chemotherapy (NAC) followed by interval debulking surgery (IDS) were at least as good as the results for patients who primary cytoreductive surgery [1-4]. Recently, NAC followed by IDS has become an alternative treatment for advancedstage ovarian cancer patients.

Bohm et al. proposed a three-tiered histopathologic scoring system for grading the response to NAC [5]. A three-tiered chemotherapy response scores (CRS) system was applied to the omental tissue sections and correlated with progression-free survival (PFS) $[5,6]$. As a

(c) The Author(s). 2020 Open Access This article is licensed under a Creative Commons Attribution 4.0 International License, which permits use, sharing, adaptation, distribution and reproduction in any medium or format, as long as you give appropriate credit to the original author(s) and the source, provide a link to the Creative Commons licence, and indicate if changes were made. The images or other third party material in this article are included in the article's Creative Commons licence, unless indicated otherwise in a credit line to the material. If material is not included in the article's Creative Commons licence and your intended use is not permitted by statutory regulation or exceeds the permitted use, you will need to obtain permission directly from the copyright holder. To view a copy of this licence, visit http://creativecommons.org/licenses/by/4.0/ The Creative Commons Public Domain Dedication waiver (http://creativecommons.org/publicdomain/zero/1.0/) applies to the data made available in this article, unless otherwise stated in a credit line to the data. 
consequence, an increasing body of research has addressed whether CRS 3 can be used as a surrogate marker, similar to the way the pathologic complete response (pCR) is used in breast cancer, in the prognosis for patients with advanced-stage ovarian cancer treated with NAC followed by IDS. However, platinum-based doublet chemotherapy remains the standard of care for advanced-stage ovarian cancer patients who are treated with NAC followed by IDS, regardless of their response to chemotherapy.

Mutations in BRCA1 and BRCA2 have been recognized as a predictor of advanced-stage ovarian cancer susceptibility and a prognostic factor [7-9]. Compared with wild-type $B R C A$ genotype patients, patients with advanced-stage ovarian cancer and BRCA1/2 mutations have been reported to have higher clinical response rates to platinum-based chemotherapy [10-12]. Therefore, there are unanswered questions about whether the higher CRS by carriers of the $B R C A 1 / 2$ germline mutations represents a better prognosis. In triple-negative breast cancers treated with NAC, several studies have tried to identify the relationships between germline $B R C A 1 / 2$ mutations, response rates, and prognoses [13, 14]. These studies have shown that patients with $B R C A 1 / 2$ mutations had superior response rates, and response rate was a weaker predictor of disease-free survival rates compared with wild-type $B R C A 1 / 2$ genotype patients.

In this study, we analyzed the extent to which CRS depended on germline BRCA1/2 mutations, whether CRS correlates with platinum-based chemotherapy, and whether CRS has an impact on survival outcomes in patients with and without germline $B R C A 1 / 2$ mutations.

\section{Methods}

\section{Study populations}

We retrospectively reviewed the medical records of 326 patients with pathologically confirmed ovarian cancer who from 2006 to 2018 received NAC at the Yonsei
Cancer Center, Seoul, South Korea. Patients with stage III or IV ovarian carcinoma who received three cycles of NAC followed by IDS were included in the study.

The exclusion criteria were as follows: Patients still receiving chemotherapy at the time of data analysis $(N=$ 19); patients who had not received IDS after NAC $(N=$ $15)$; patients for whom data was missing $(N=31)$; and, lastly, patients who had not undergone a germline $B R C A$ test $(N=92)$. After this review, 169 patients met our criteria. Of these, 122 patients had the wild-type $B R C A$ genotype, and 47 had BRCA1 or BRCA2 mutations (Fig. 1).

\section{Treatment}

Most patients received taxane (paclitaxel, docetaxel) and platinum (carboplatin) combination chemotherapy and some patients received paclitaxel, carboplatin and bevacizumab combination chemotherapy. Other treatments such as radiation or endocrine therapy were not performed before surgery. Determination of which patients required NAC was based on initial imaging studies that showed high tumor dissemination with high risk of postoperative comorbidities and poor performance status, or optimal cytoreduction surgery (residual disease measuring $1 \mathrm{~cm}$ or less) was unsuitable because of a high tumor burden [predictive index value (PIV) $\geq 8$ ] [15]. For diagnostic laparoscopy, the degree of tumor burden was determined with the PIV [16]. For IDS, all patients underwent surgery with the intent to achieve complete resection with no residual tumor. Standard surgical procedures included hysterectomy, bilateral oophorectomy, omentectomy, pelvic/para-aortic lymph node dissection, and appendectomy. Radical surgery included more aggressive procedures such as liver resection or bowel resection than those who underwent standard surgical procedures [17]. Subsequently, additional cycles of adjuvant chemotherapy were administered to complete a total of six cycles at the discretion of the treating

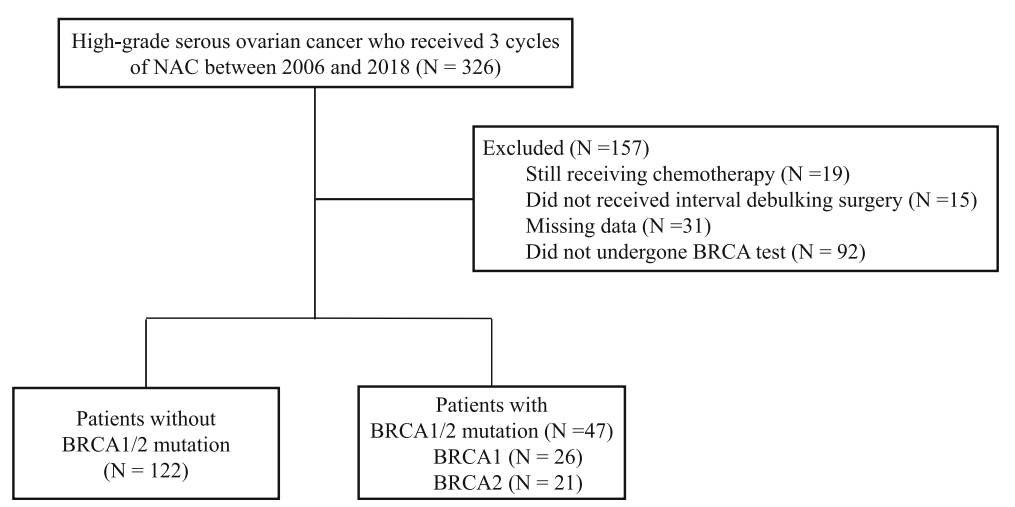

Fig. 1 Flow diagram of the study population. NAC, neoadjuvant chemotherapy 
physician. Surgical complexity was classified as low, intermediate, or high [18].

\section{Pathologic review}

The resected tissues were formalin-fixed and paraffinembedded, and stained with hematoxylin and eosin (H\&E) in the Department of Pathology, Severance Hospital, Yonsei University College of Medicine. Three expert gynecologic pathologists reviewed all available H\&E-stained slides obtained from IDS tissues. They independently scored each slide according to the threetiered CRS system described by Böhm et al. [5]. Briefly, CRS is defined as follows: CRS 1: No or minimal tumor response; CRS 2: Partial tumor response: CRS 3: Complete or near-complete tumor response.

\section{$B R C A$ testing}

From the whole blood samples, genomic DNA was extracted according to the protocol provided by the manufacturer (QIAamp DNA Blood Mini Kit, QIAGEN, USA). To assess the germline mutations in BRCA1 and $B R C A 2$, the entire coding region and intron-exon boundaries of two genes were amplified using polymerase chain reaction (PCR) amplification. We identified all variants using Sanger sequencing on a 3730 DNA Analyzer with the BigDye Terminator v3.1 Cycle Sequencing Kit (Applied Biosystems, Foster City, CA, USA). Sequencing data were aligned against appropriate reference sequences (accession numbers NM_007294 and NM_000059, respectively) and analyzed using the Sequencher 5.3 software (Gene Codes Corp., Ann Arbor, MI, USA). Variations were described following the nomenclature system of the Human Genome Variation Society (http://www.hgvs.org/mutnomen) and the conventional nomenclature system from the Breast Cancer Information Core (BIC; http://research.nhgri.nih. gov/bic/). Pathogenicity interpretation of the variants were performed according to 2015 American College of Medical Genetics and Genomics guideline by professional medical geneticists, using evidences of variant type assessment, population allele frequency, prediction algorithm results, and database search such as Human Gene Mutation Database, ClinVar, and BIC.

\section{Statistical analysis}

Descriptive data are reported as the median (range) or frequency (percentage). Categorical variables were compared with the chi-square or continuous variables with the Student's t-test or Mann-Whitney U test for parametric/non-parametric variables, respectively. Responses were assessed according to the Response Evaluation Criteria in Solid Tumors criteria, version 1.1. We defined PFS as the time from the date of diagnosis to disease progression or death; overall survival (OS) was measured from the date of diagnosis to death or to the date of the last follow-up. Survival analysis was performed using the Kaplan-Meier method with a log-rank test. For all analyses, the significance level was set at 0.05 . The statistical analyses were performed with the SPSS statistical software (version 21.0; IBM Corp., Armonk, NY).

\section{Results \\ Patients' characteristics}

Table 1 contains a comparison of the clinical characteristics between the $B R C A$ wild-type genotype group and the $B R C A$ mutation group. Of the 169 patients included, $122(71.9 \%)$ had the wild-type $B R C A$ genotype, and 47 (28.1\%) had the BRCA1/2 mutations. There were no significant between-group differences in patient characteristics such as age, CA-125 level, FIGO stage, histologic type, tumor grade, tumor burden, CRS, residual disease, rate of radical surgery, surgical complexity score, chemotherapy regimen, or cycles of NAC.

\section{CRS relative to $B R C A 1 / 2$ mutation status}

CRS 3 patients were $43(35.2 \%)$ and 16 (34.0\%) for patients without and with $B R C A 1 / 2$ mutations, respectively $(P=0.516)$ (Table 2). Although CRS 3 rates differed between BRCA1 (26.9\%), BRCA2 (42.9\%) and the wild-type $B R C A$ genotype, these difference did not achieve statistical significance.

Kaplan-Meier curves for OS and PFS stratified by CRS in patients with the BRCA1/2 mutations are shown in Fig. 2. Fifteen (48.4\%) in the CRS $1 / 2$ and 8 (50.0\%) in the CRS 3 group had recurred by the time of the analysis. Median PFS in the CRS $1 / 2$ group was 21.7 months (95\% confidence interval [CI], 16.2-33.3) and 22.0 months (95\% CI, 14.4-29.6) in the CRS 3 group. Four (12.9\%) in the CRS1/2 and no patients in the CRS3 group had died by the time of the analysis. Median OS was not reached in both groups. CRS 3 in patients with the $B R C A 1 / 2$ mutations was not significantly associated with improved PFS $(P=0.949)$ and OS $(P=0.168)$. In patients without $B R C A$ mutations, $52(65.8 \%)$ in the CRS $1 / 2$ and $24(55.8 \%)$ in the CRS 3 group had recurred by the time of the analysis. Median PFS in the CRS $1 / 2$ group was 17.2 months (95\% CI, 14.7-19.7) and 22.4 months (95\% CI, 14.5-30.3). Eighteen (22.8\%) in the CRS $1 / 2$ and $5(11.6 \%)$ patients in the CRS 3 group had died by the time of the analysis. Median OS in the CRS $1 / 2$ group was 96.4 months $(95 \%$ C], 27.1-165.7) and not reached in the CRS 3 group. However, CRS 3 in patients without $B R C A$ mutations was significantly associated with improved PFS $(P=0.030)$ and OS $(P=0.039)$ (Fig. 3). The results of the multivariate Cox regression analyses of PFS and OS in all patients are shown in Additional file 1 . In terms of recurrence, multivariate analysis showed that BRCA1/2 mutation was a marginally 
Table 1 Patient and clinical characteristics $(N=169)$

\begin{tabular}{|c|c|c|c|}
\hline Characteristics & $B R C A$ wild-type $(N=122)$ & $B R C A$ mutation $(N=47)$ & $P$ \\
\hline Age, median (range), years & $57(32-77)$ & $56(27-76)$ & 0.610 \\
\hline CA-125 level, median (range), U/mL & $1958.7(94.2 .0-21,994.8)$ & $1711.3(75.0-23,919.0)$ & 0.759 \\
\hline \multicolumn{4}{|l|}{ FIGO stage, n (\%) } \\
\hline III & $56(45.9 \%)$ & $23(48.9 \%)$ & \multirow[t]{2}{*}{0.734} \\
\hline IV & $66(54.4 \%)$ & $24(51.1 \%)$ & \\
\hline \multicolumn{4}{|l|}{ Grading } \\
\hline 1 & $3(2.5 \%)$ & $0(0 \%)$ & \multirow[t]{4}{*}{0.489} \\
\hline 2 & $11(9.0 \%)$ & $2(4.5 \%)$ & \\
\hline 3 & $102(83.6 \%)$ & $42(89.4 \%)$ & \\
\hline Not available & $6(4.9 \%)$ & $3(6.4 \%)$ & \\
\hline \multicolumn{4}{|c|}{ Tumor burden assessed by diagnostic laparoscopy* } \\
\hline PIV 8 & $27(22.1 \%)$ & $3(6.4 \%)$ & \multirow[t]{5}{*}{0.097} \\
\hline PIV 10 & $25(20.5 \%)$ & $14(29.8 \%)$ & \\
\hline PIV 12 & $10(8.2 \%)$ & $4(8.5 \%)$ & \\
\hline PIV 14 & $5(4.1 \%)$ & $1(2.1 \%)$ & \\
\hline Not available & $55(45.1 \%)$ & $25(53.2 \%)$ & \\
\hline \multicolumn{4}{|l|}{ CRS, n (\%) } \\
\hline $1-2$ & $79(64.8 \%)$ & $31(66.0 \%)$ & \multirow[t]{2}{*}{0.516} \\
\hline 3 & $43(35.2 \%)$ & $16(34.0 \%)$ & \\
\hline \multicolumn{4}{|l|}{ Residual disease, n (\%) } \\
\hline No & $62(50.8 \%)$ & $18(38.3 \%)$ & \multirow[t]{3}{*}{0.344} \\
\hline Any residual & $58(47.5 \%)$ & $28(59.6 \%)$ & \\
\hline Not available & $2(1.6 \%)$ & $1(2.1 \%)$ & \\
\hline \multicolumn{4}{|l|}{ Radical surgery ${ }^{\dagger}, \mathrm{n}(\%)$} \\
\hline None & $59(48.4 \%)$ & 19 (40.4\%) & \multirow[t]{2}{*}{0.354} \\
\hline Any radical surgery & $63(51.6 \%)$ & $28(59.6 \%)$ & \\
\hline \multicolumn{4}{|l|}{ Surgical complexity score groups ${ }^{\ddagger}$} \\
\hline 1-2 (Low/intermediate) & $102(83.6 \%)$ & 37 (78.7\%) & \multirow[t]{2}{*}{0.457} \\
\hline 8 (High) & $20(16.4 \%)$ & $10(21.3 \%)$ & \\
\hline \multicolumn{4}{|l|}{ Chemotherapy regimen, n (\%) } \\
\hline Paclitaxel + carboplatin & $91(74.6 \%)$ & $34(72.3 \%)$ & \multirow[t]{4}{*}{0.576} \\
\hline Docetaxel + carboplatin & $8(6.6 \%)$ & $6(12.8 \%)$ & \\
\hline Weekly paclitaxel + carboplatin & $15(12.3 \%)$ & $5(10.6 \%)$ & \\
\hline Paclitaxel + carboplatin + bevacizumab & $8(6.6 \%)$ & 2 (4.3\%) & \\
\hline
\end{tabular}

*According to Fagotti et al. [15]

${ }^{+}$Radical surgery includes any of following: bowel surgery, cholecystectomy, diaphragm peritonectomy/resection, distal pancreatectomy video-assisted

thoracoscopic surgery, splenectomy, liver resection, supraclavicular fossa resection, ureter resection, and others

₹ According to Aletti et al. [19]

CA-125, cancer antigen 125; FIGO, International Federation of Gynecology and Obstetrics; HGSC, high-grade serous carcinoma; PIV, predictive index value; CRS,

chemotherapy response score

significant prognostic factor (HR, 0.65; 95\% CI, $0.40-$ 1.04). Multivariate analysis showed CRS 3 (HR, 0.29; 95\% CI, 0.10-0.80) and BRCA1/2 mutation (HR, 0.27; $95 \% \mathrm{CI}, 0.08-0.92$ ) were significantly associated with a longer OS.

We also categorized the patients based on $B R C A \mathrm{mu}$ tations and CRS (BRCA1/2 mutations with CRS 1/2; the wild-type $B R C A$ genotype with CRS $1 / 2 ; B R C A 1 / 2$ mutations with CRS 3; and the wild-type $B R C A$ genotype with CRS 3) to evaluate survival according to the relationship of BRCA1/2 mutations in the CRS. Fifteen (48.4\%) in BRCA1/2 mutations with CRS1/2, $52(65.8 \%)$ in the wild-type $B R C A$ genotype with CRS1/2, 8 (50\%) in $B R C A 1 / 2$ mutations with CRS3, and $24(55.8 \%)$ in the 
Table 2 Chemotherapy response score relative to BRCA1/2 mutation status

\begin{tabular}{llllll}
\hline & CRS & Wild type & Mutation & Total & $P$ value \\
\hline BRCA1 or 2 & $1-2$ & $79(64.8 \%)$ & $31(66.0 \%)$ & $110(65.1 \%)$ & 0.516 \\
& 3 & $43(35.2 \%)$ & $16(34.0 \%)$ & $59(34.9 \%)$ & \\
BRCA1 & $1-2$ & $91(63.6 \%)$ & $19(73.1 \%)$ & $110(65.1 \%)$ & 0.243 \\
& 3 & $52(36.6 \%)$ & $7(26.9 \%)$ & $59(34.9 \%)$ & \\
BRCA2 & $1-2$ & $98(66.2 \%)$ & $12(57.1 \%)$ & $110(65.1 \%)$ & 0.280 \\
& 3 & $50(33.8 \%)$ & $9(42.9 \%)$ & $59(34.9 \%)$ & \\
\hline
\end{tabular}

CRS, Chemotherapy response score

wild-type $B R C A$ genotype with CRS3 group had recurred by the time of the analysis. Median PFS in 4 groups were 21.7 (95\% CI, 16.2-33.3), 17.2 (95\% CI, 14.7-19.7), 22.0 (95\% CI, 14.4-29.6), and 22.4 (95\% CI, 14.5-30.3), respectively. Three (9.7\%) in BRCA1/2 mutations with CRS1/2, $18(22.8 \%)$ in the wild-type $B R C A$ genotype with CRS1/2, $0(0 \%)$ in BRCA1/2 mutations with CRS3, and $5(11.6 \%)$ in the wild-type $B R C A$ genotype with CRS3 group had died by the time of the analysis. Median OS in the BRCA1/2 mutations with CRS3 group was 96.4 and other 3 groups were not reached. In patients with CRS $1 / 2$, the carriers of $B R C A 1 / 2$ mutations had better PFS $(P=0.044)$ and OS $(P=0.043)$ than the wildtype $B R C A$ genotype patients. However, in patients with CRS 3, there was no significant difference in PFS $(P=$ $0.863)$ and $\operatorname{OS}(P=0.216)$ between $B R C A 1 / 2$ carriers and the wild-type $B R C A$ genotype patients (Fig. 4). In addition, we performed a subset analysis including only in Grade 3 patients excluding the 16 patients with Grade1 or 2. Similar results were obtained for patients with Grade 3 (Additional file 2). In patients with CRS 1/ 2 , the carriers of $B R C A 1 / 2$ mutations had better PFS $(P=0.015)$ and $\mathrm{OS}(P=0.049)$ than the wild-type $B R C A$ genotype patients. However, in patients with CRS 3, there was no significant difference in PFS $(P=0.917)$ and OS $(P=0.389)$ between $B R C A 1 / 2$ carriers and the wild-type $B R C A$ genotype patients.

\section{Discussion}

In this study, we evaluated the relationship between BRCA1/2 mutations and CRS and survival outcomes in advanced-stage ovarian cancer patients treated with NAC followed by IDS. The patients with $B R C A 1 / 2 \mathrm{mu}-$ tations did not show higher CRS rates than patients without these mutations. In patients without the BRCA1/2 mutations, the CRS 3 patients showed superior survival outcomes compared to the patients with CRS 1/ 2 . In addition, in the CRS $1 / 2$ patient group, the survival outcomes of the BRCA1/2 carriers were superior to those of the wild-type $B R C A$ genotype patients. In the $B R C A$ wild-type group, patients who achieved CRS $1 / 2$ after NAC had a poor prognoses compared to the patients with CRS 3. Therefore, patients with the BRCA wild-type should be considered for additional treatments
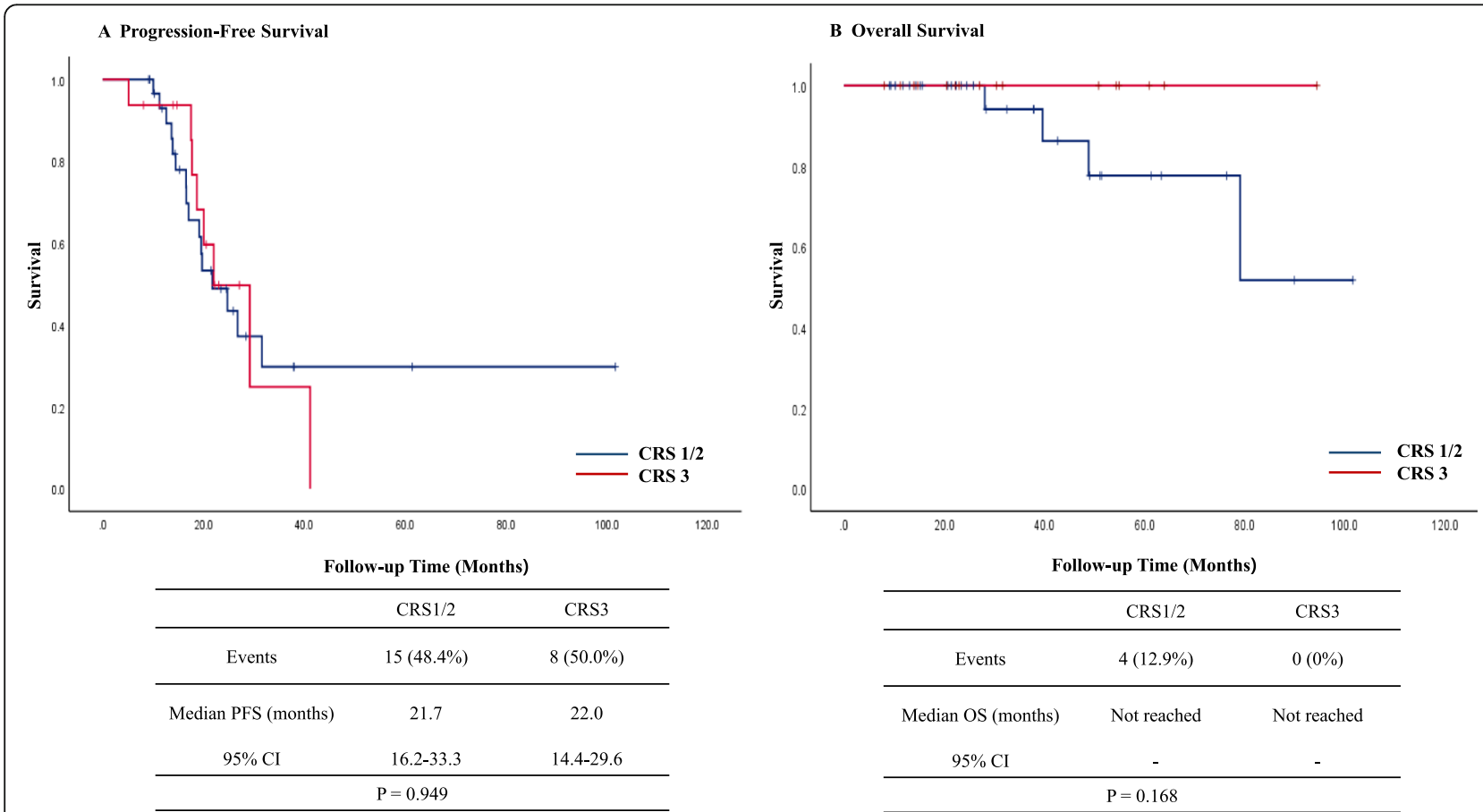

Fig. 2 Kaplan-Meier curves of PFS (a) and OS (b) stratified by CRS in patients with BRCA1/2 mutations. Cl, confidence interval; CRS, chemotherapy response score; PFS, progression-free survival; OS, overall survival 

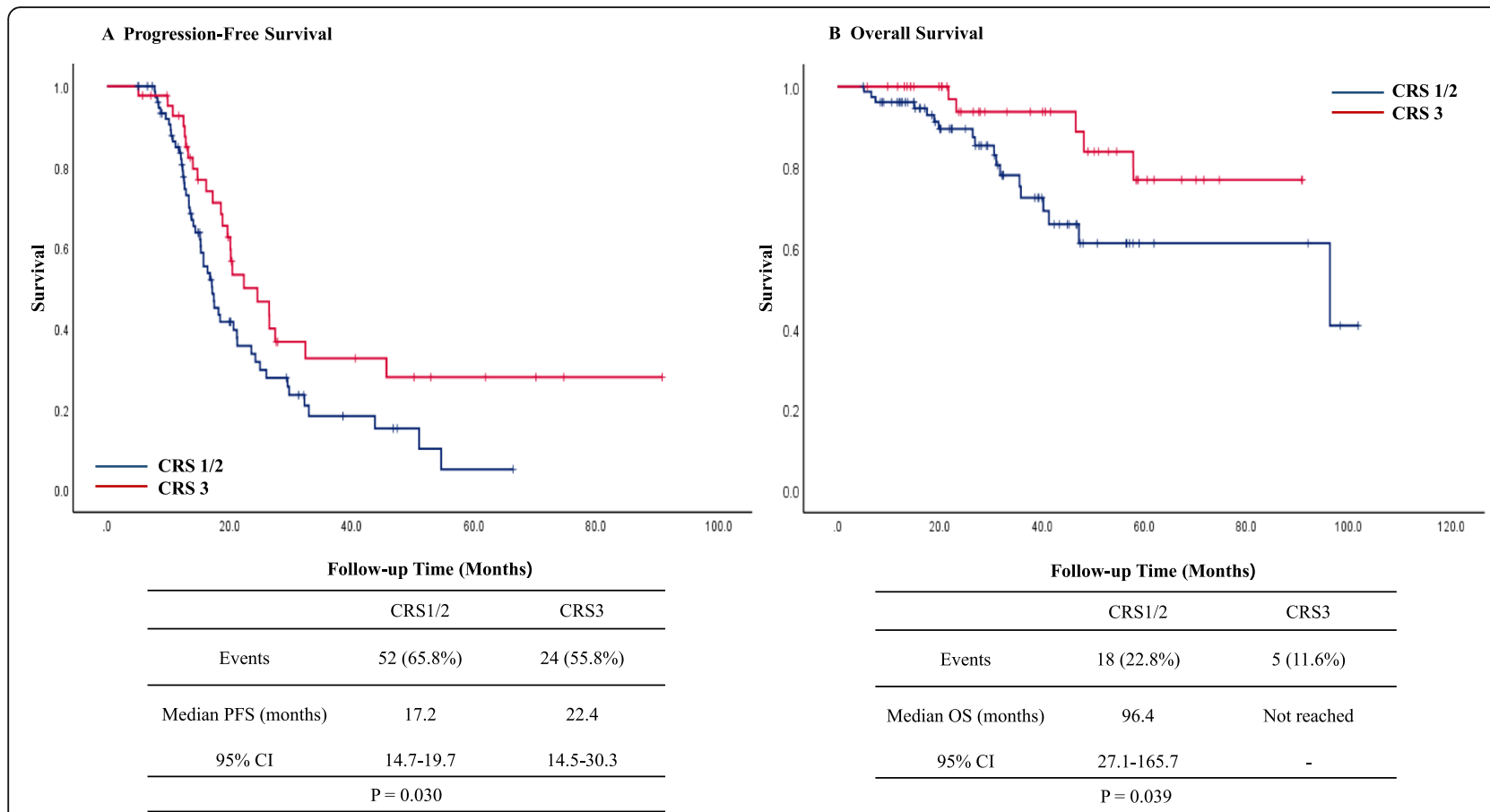

Fig. 3 Kaplan-Meier curves of PFS (a) and OS (b) stratified by CRS in patients without BRCA mutations. Cl, confidence interval; CRS, chemotherapy response score; PFS, progression-free survival; OS, overall survival
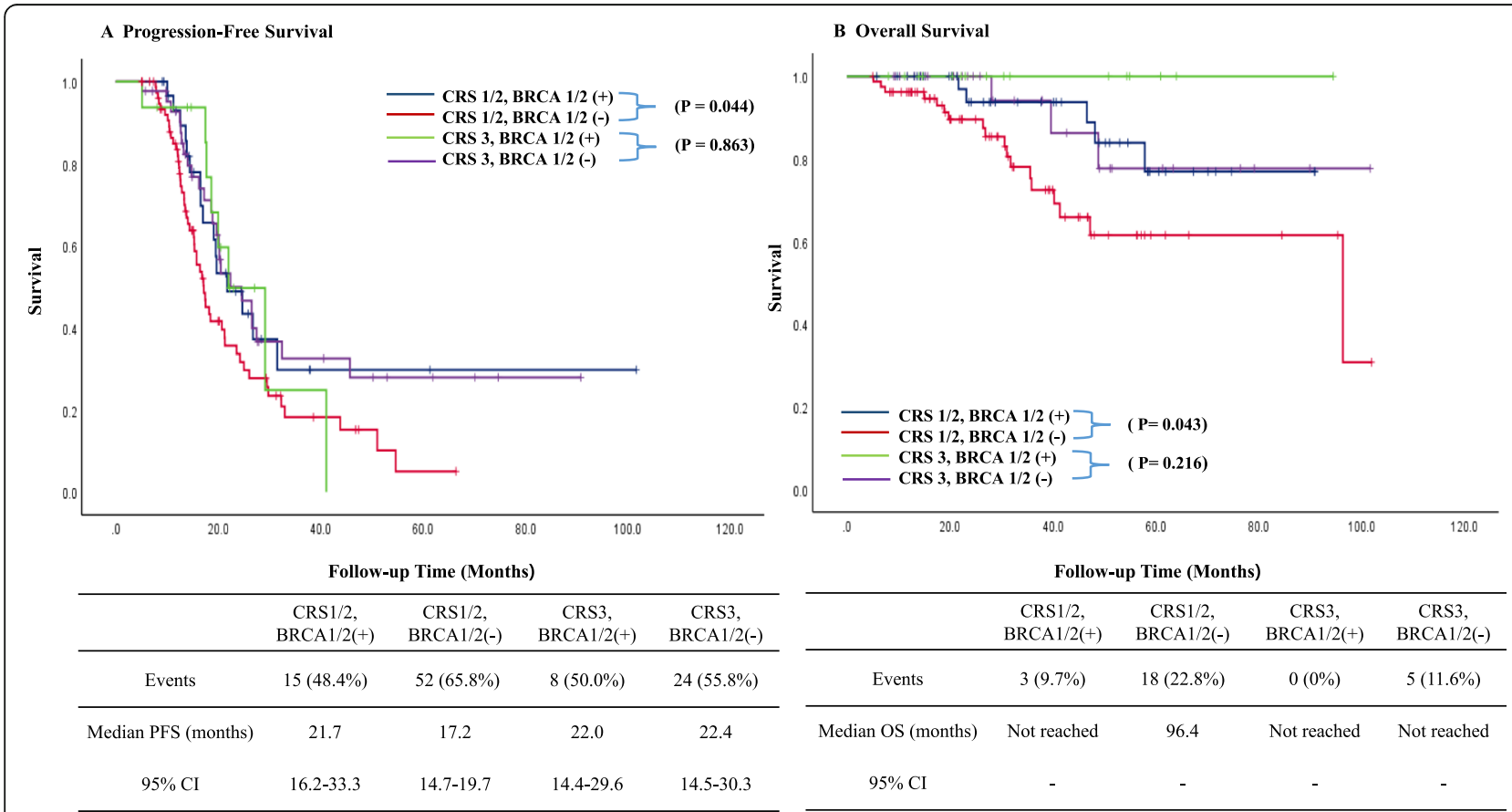

Fig. 4 Kaplan-Meier curves of PFS (a) and OS (b) stratified by BRCA mutations and CRS. Cl, confidence interval; CRS, chemotherapy response score; PFS, progression-free survival; OS, overall survival 
to achieve CRS 3 after NAC, such as adding a bevacizumab or immune checkpoint inhibitors to platinumbased NAC. In addition, BRCA wild-type patients with CRS $1 / 2$ after platinum-based NAC expected to have a poor prognosis due to residual tumors after NAC that may be resistant to platinum-based NAC if they receive the same NAC regimen after IDS. To improve the survival of the BRCA wild-type patients with CRS $1 / 2$, the genomic profiles of the post-NAC tissues should be evaluated to identify biomarkers and to select targeted therapies [19].

Response rates to platinum-based NAC predict survival and may be regarded as a surrogate prognostic marker $[5,6]$. A three-tiered CRS system showed a significant association with survival outcomes. The CRS system for assessing platinum-based NAC response rates can be a reproducible prognostic tool, and the incorporation of the CRS system after NAC can help determination of adjuvant treatment in advanced-stage ovarian cancer patients. Previous studies [10-12] showed that advanced-stage ovarian cancer patients with $B R C A 1 / 2$ mutations tend to have higher response rates to platinum-based chemotherapy, longer PFS, and a higher benefit from NAC. The BRCA1/2 mutations are also being considered as specific targets. Recent randomized studies on poly (adenosine diphosphate-ribose) polymerase inhibitors have demonstrated a substantial survival benefit in $B R C A 1 / 2$ carriers [20-24], hence germline $B R C A 1 / 2$ testing is becoming a mandatory in treatment decisions in advanced-stage ovarian cancer.

In triple-negative breast cancer, several studies have shown that in the relationships between germline $B R C A 1 / 2$ mutations, response rates, and prognoses. In patients with triple-negative breast cancer, BRCA1/2 mutation patients had higher $\mathrm{PCR}$ rates than those with $B R C A$ wild-type patients. However, $B R C A$ mutation patients do not benefit as much from a pCR compared with patients without $B R C A$ mutation. In ovarian cancer patients, no such studies have yet been reported. Hahnen et al. [13] showed that triple-negative breast cancer patients without germline BRCA1/2 mutations benefit from the addition of carboplatin and that $B R C A 1 / 2 \mathrm{mu}-$ tation carriers had superior response rates. Fasching et al. [14] showed the effect of BRCA1/2 mutations in the NAC of triple-negative breast cancer. Patients with $B R C A 1$ or $B R C A 2$ mutations had higher $\mathrm{pCR}$ rates than patients without a mutation. However, BRCA1/2 mutation patients who receive standard treatment do not benefit as much from a pCR as patients with the wildtype $B R C A$. These results were similar to our study.

Our study showed that patients with $B R C A 1 / 2$ mutations enjoyed a good survival outcome regardless of their CRS. In contrast, CRS 3 had a significant survival benefit on PFS and OS for wild-type BRCA genotype patients.
In addition, the $B R C A 1 / 2$ mutations had a significant influence on survival in the CRS $1 / 2$ patient group. One plausible explanation for the absence of the effect of CRS 3 on the prognoses for patients with the BRCA1/2 mutations is the influence of the platinum-based adjuvant treatment after IDS. Although the CRS 1/2 group of patients was expected to have a poor prognosis, their prospects were improved if they had the BRCA1/2 mutations because of their conferred sensitivity to platinumbased adjuvant chemotherapy after IDS. The mechanism of action by platinum drugs is mediated by the formation of the covalent binding of platinum to DNA. This binding interferes with DNA synthesis and ultimately leads to cell death [25]. It seems likely that partially formed covalent bindings cause replication of fork stalling when it is encountered by the DNA replication machinery during the $S$ phase. These stalled replication forks may degenerate into double-stranded DNA breaks [26] in which tumor cells with defects in their DNA repair pathways achieves increased response rates against platinum drugs, as investigated in previous studies [27-30].

However, unlike in breast cancer studies, the status of BRCA1/2 mutations in our study was unrelated to CRS. In previous studies [31, 32], patients with germline $B R C A 1 / 2$ mutations were associated with wider disease diffusion than $B R C A$ wild-type patients in terms of peritoneal spread and incidence of bulky lymph nodes. Furthermore, Soslow et al. [33] showed the correlations between the genotype and characteristic morphologic appearance of ovarian cancer. The BRCA1 mutation group had more tumor-infiltrating lymphocytes, thus suggesting that the status of $B R C A$ mutations could influence the immunological microenvironment sufficiently to eventually drive the specific characteristics of disease presentation. Therefore, BRCA1/2 mutation carriers may have a lower CRS following NAC as compared to $B R C A$ wild-type patients.

The main limitation of our study was its low sample size and the small number of patients with BRCA1/2 mutations. Although 169 patients were genotyped, there were only 47 carriers of these mutations. Second, considering the family history of patients who were diagnosed with ovarian cancer before 2017, the germline $B R C A$ test was recommended for patients with a high probability of being a $B R C A 1 / 2$ mutation carrier. Olaparib treatment in the maintenance setting has been covered by Korean National Health Insurance since 2017 , we have been routinely offered the germline $B R C A$ test in patients diagnosed with high-grade serous ovarian cancer. In addition, because 92 people did not receive $B R C A$ test during the study period, a selection bias may have influenced the outcomes. Third, NAC was only incorporated into our institution in late 2010; thus, our 
cohort was limited by the short follow-up period. Fourth, the type of NAC is important because CRS is affected by the response to chemotherapy. About $75 \%$ of patients received paclitaxel and carboplatin combination chemotherapy in our study, an analysis of the relationship between CRS and the type of NAC could not be conducted. $\$.

\section{Conclusion}

In conclusion, in advanced-stage ovarian cancer patients treated with NAC followed by IDS, CRS 3 was not associated with increased survival for BRCA1/2 mutation carriers than for patients without these mutations. Additional studies are needed to elucidate the effect of CRS on prognoses in advanced-stage ovarian cancer patients with and without $B R C A 1 / 2$ mutations.

\section{Supplementary information}

Supplementary information accompanies this paper at https://doi.org/10. 1186/s12885-020-6688-8

Additional file 1. Multivariate analyses for progression-free and overall survival using a Cox proportional hazards model.

Additional file 2.

\section{Abbreviations}

CRS: Chemotherapy response scores; IDS: Interval debulking surgery; NAC: Neoadjuvant chemotherapy; OS: Overall survival; pCR: Pathologic complete response; PCR: Polymerase chain reaction; PFS: Progression-free survival; PIV: Predictive index value

\section{Acknowledgments}

None.

\section{Author contributions}

Conceptualization: L.Y.J., L.J.Y., K.S.H.; Methodology: L.Y.J., L.J.Y.; Validation: L.Y.J.; Formal analysis and investigation: L.Y.J.; Resources and data curation: L.Y.J., K.H.S., R.J.H; Writing - original draft preparation: L.Y.J.; Writing - review and editing: L.J.Y., N.E.J.; Supervision: N.E.J., K.S.W., K.Y.T.; Project administration: L.Y.J., L.J.Y.; Funding acquisition: L.J.Y. All authors have read and approved the manuscript.

\section{Funding}

This study was supported by a faculty research grant of Yonsei University College of Medicine for 6-2018-0169. Research grants are administered by the Ministry of Science, ICT \& Future Planning (2017M3A9E8029714). This funding source had no role in study design, data collection and analysis, and interpretation of data and in writing the manuscript.

\section{Availability of data and materials}

The datasets used and analyzed during the current study are available from the corresponding author on reasonable request.

\section{Ethics approval and consent to participate}

The need for an approval was waived by the 'Institutional Review Board of Severance Hospital at Yonsei University College of Medicine' as the study was retrospective and individual patients were not identifiable.

\section{Consent for publication}

Not applicable.

\section{Competing interests}

The authors declare that they have no conflicts of interest.

\section{Author details}

'Department of Obstetrics and Gynecology, Institute of Women's Life Medical Science, Yonsei University College of Medicine, 50-1 Yonsei-ro, Seodaemun-gu, 03722 Seoul, Republic of Korea. ${ }^{2}$ Department of Pathology, Severance Hospital, Yonsei University College of Medicine, Seoul, South Korea. ${ }^{3}$ Department of Laboratory Medicine, Severance Hospital, Yonsei University College of Medicine, Seoul, South Korea.

Received: 10 November 2019 Accepted: 27 February 2020

Published online: 04 March 2020

\section{References}

1. Onda T, Matsumoto K, Shibata T, Sato A, Fukuda H, Konishi I, Kamura T, Yoshikawa H. Phase III trial of upfront debulking surgery versus neoadjuvant chemotherapy for stage III/IV ovarian, tubal and peritoneal cancers: Japan clinical oncology group study JCOG0602. Jpn J Clin Oncol. 2008;38(1):74-7.

2. Vergote I, Trope CG, Amant F, Kristensen GB, Ehlen T, Johnson N, Verheijen $\mathrm{RH}$, van der Burg ME, Lacave AJ, Panici PB, et al. Neoadjuvant chemotherapy or primary surgery in stage IIIC or IV ovarian cancer. N Engl J Med. 2010; 363(10):943-53.

3. Kehoe S, Hook J, Nankivell M, Jayson GC, Kitchener H, Lopes T, Luesley D, Perren T, Bannoo S, Mascarenhas M, et al. Primary chemotherapy versus primary surgery for newly diagnosed advanced ovarian cancer (CHORUS): an open-label, randomised, controlled, non-inferiority trial. Lancet. 2015; 386(9990):249-57.

4. Fagotti A, Ferrandina G, Vizzielli G, Fanfani F, Gallotta V, Chiantera V, Costantini B, Margariti PA, Gueli Alletti S, Cosentino F, et al. Phase III randomised clinical trial comparing primary surgery versus neoadjuvant chemotherapy in advanced epithelial ovarian cancer with high tumour load (SCORPION trial): final analysis of peri-operative outcome. Eur J Cancer. 2016;59:22-33.

5. Bohm S, Faruqi A, Said I, Lockley M, Brockbank E, Jeyarajah A, Fitzpatrick A, Ennis D, Dowe T, Santos JL, et al. Chemotherapy response score: development and validation of a system to quantify Histopathologic response to Neoadjuvant chemotherapy in Tubo-ovarian high-grade serous carcinoma. J Clin Oncol. 2015;33(22):2457-63.

6. Lee JY, Chung YS, Na K, Kim HM, Park CK. External validation of chemotherapy response score system for histopathological assessment of tumor regression after neoadjuvant chemotherapy in tubo-ovarian highgrade serous carcinoma 2017; https://doi.org/10.3802/jgo.2017.28.e73.

7. Antoniou A, Pharoah PD, Narod S, Risch HA, Eyfjord JE, Hopper JL, Loman N, Olsson $\mathrm{H}$, Johannsson $\mathrm{O}$, Borg A, et al. Average risks of breast and ovarian cancer associated with BRCA1 or BRCA2 mutations detected in case series unselected for family history: a combined analysis of 22 studies. Am J Hum Genet. 2003;72(5):1117-30.

8. Chen S, Parmigiani G. Meta-analysis of BRCA1 and BRCA2 penetrance. J Clin Oncol. 2007;25(11):1329-33.

9. Huang YW. Association of BRCA1/2 mutations with ovarian cancer prognosis: an updated meta-analysis. Medicine (Baltimore). 2018;97(2):e9380.

10. Alsop K, Fereday S, Meldrum C, de Fazio a, Emmanuel C, George J, Dobrovic a, Birrer MJ, Webb PM, Stewart C, et al. BRCA mutation frequency and patterns of treatment response in BRCA mutation-positive women with ovarian cancer: a report from the Australian ovarian Cancer study group. J Clin Oncol. 2012;30(21):2654-63.

11. Mahdi H, Gockley A, Esselen K, Marquard J, Nutter B, Yang B, Hinchcliff E, Horowitz N, Rose PG. Outcome of neoadjuvant chemotherapy in BRCA1/2 mutation positive women with advanced-stage Mullerian cancer. Gynecol Oncol. 2015;139(3):407-12.

12. Gorodnova TV, Sokolenko AP, Ivantsov AO, Iyevleva AG, Suspitsin EN, Aleksakhina SN, Yanus GA, Togo AV, Maximov SY, Imyanitov EN. High response rates to neoadjuvant platinum-based therapy in ovarian cancer patients carrying germ-line BRCA mutation. Cancer Lett. 2015;369(2):363-7.

13. Hahnen E, Lederer B, Hauke J, Loibl S, Krober S, Schneeweiss A, Denkert C, Fasching PA, Blohmer JU, Jackisch C, et al. Germline mutation status, pathological complete response, and disease-free survival in triple-negative breast Cancer: secondary analysis of the GeparSixto randomized clinical trial. JAMA Oncol. 2017;3(10):1378-85.

14. Fasching PA, Loibl S, Hu C, Hart SN, Shimelis H, Moore R, Schem C, Tesch H, Untch $M$, Hilfrich J, et al. BRCA1/2 mutations and Bevacizumab in the Neoadjuvant treatment of breast Cancer: response and prognosis results in 
patients with triple-negative breast Cancer from the GeparQuinto study. J Clin Oncol. 2018;36(22):2281-7.

15. Lee YJ, Lee JY, Cho MS, Nam EJ, Kim SW, Kim S, Kim YT. Incorporation of paclitaxel-based hyperthermic intraperitoneal chemotherapy in patients with advanced-stage ovarian cancer treated with neoadjuvant chemotherapy followed by interval debulking surgery: a protocol-based pilot study. J Gynecol Oncol. 2019;30(1):e3.

16. Fagotti A, Ferrandina G, Fanfani F, Garganese G, Vizzielli G, Carone V, Salerno MG, Scambia G. Prospective validation of a laparoscopic predictive model for optimal cytoreduction in advanced ovarian carcinoma. Am J Obstet Gynecol. 2008;199(6):642.e1-6.

17. Lee YJ, Chung YS, Lee JY, Nam EJ, Kim SW, Kim S, Kim YT. Impact of the time interval from completion of neoadjuvant chemotherapy to initiation of postoperative adjuvant chemotherapy on the survival of patients with advanced ovarian cancer. Gynecol Oncol. 2018;148(1):62-7.

18. Aletti GD, Eisenhauer EL, Santillan A, Axtell A, Aletti G, Holschneider C, Chi DS, Bristow RE, Cliby WA. Identification of patient groups at highest risk from traditional approach to ovarian cancer treatment. Gynecol Oncol. 2011;120(1):23-8.

19. Lee YJ, Kim D, Shim JE, Bae SJ, Jung YJ, Kim S, Lee H, Kim SH, Jo SB, Lee JY, et al. Genomic profiling of the residual disease of advanced high-grade serous ovarian cancer after neoadjuvant chemotherapy. Int J Cancer. 2020; 146(7):1851-61.

20. Coleman RL, Oza AM, Lorusso D, Aghajanian C, Oaknin A, Dean A, Colombo N, Weberpals JI, Clamp A, Scambia G, et al. Rucaparib maintenance treatment for recurrent ovarian carcinoma after response to platinum therapy (ARIEL3): a randomised, double-blind, placebo-controlled, phase 3 trial. Lancet. 2017;390(10106):1949-61.

21. Kaufman B, Shapira-Frommer R, Schmutzler RK, Audeh MW, Friedlander M, Balmana J, Mitchell G, Fried G, Stemmer SM, Hubert A, et al. Olaparib monotherapy in patients with advanced cancer and a germline BRCA1/2 mutation. J Clin Oncol. 2015;33(3):244-50.

22. Ledermann J, Harter P, Gourley C, Friedlander M, Vergote I, Rustin G, Scott CL, Meier W, Shapira-Frommer R, Safra T, et al. Olaparib maintenance therapy in patients with platinum-sensitive relapsed serous ovarian cancer: a preplanned retrospective analysis of outcomes by BRCA status in a randomised phase 2 trial. Lancet Oncol. 2014;15(8):852-61.

23. Mirza MR, Monk BJ, Herrstedt J, Oza AM, Mahner S, Redondo A, Fabbro M, Ledermann JA, Lorusso D, Vergote I, et al. Niraparib maintenance therapy in platinum-sensitive, recurrent ovarian Cancer. N Engl J Med. 2016;375(22): 2154-64.

24. Moore K, Colombo N, Scambia G, Kim BG, Oaknin A, Friedlander M, Lisyanskaya A, Floquet A, Leary A, Sonke GS, et al. Maintenance Olaparib in patients with newly diagnosed advanced ovarian Cancer. N Engl J Med. 2018. https://doi.org/10.1056/NEJMoa1810858.

25. Nafisi S, Norouzi Z. A comparative study on the interaction of cis- and transplatin with DNA and RNA. DNA Cell Biol. 2009;28(9):469-77.

26. Lord CJ, Garrett MD, Ashworth A. Targeting the double-strand DNA break repair pathway as a therapeutic strategy. Clin Cancer Res. 2006;12(15):4463-8.

27. Sirohi B, Arnedos M, Popat S, Ashley S, Nerurkar A, Walsh G, Johnston S, Smith IE. Platinum-based chemotherapy in triple-negative breast cancer. Ann Oncol. 2008;19(11):1847-52.

28. Beheshti F, Hassanian SM, Khazaei M, Hosseini M, ShahidSales S, Hasanzadeh M, Maftouh M, Ferns GA, Avan A. Genetic variation in the DNA repair pathway as a potential determinant of response to platinum-based chemotherapy in breast cancer. J Cell Physiol. 2018;233(4):2752-8.

29. Zhao EY, Shen Y, Pleasance E, Kasaian K, Leelakumari S, Jones M, Bose P, Ch'ng C, Reisle C, Eirew P, et al. Homologous recombination deficiency and platinum-based therapy outcomes in advanced breast Cancer. Clin Cancer Res. 2017;23(24):7521-30.

30. Arun B, Bayraktar S, Liu DD, Gutierrez Barrera AM, Atchley D, Pusztai L, Litton JK, Valero V, Meric-Bernstam F, Hortobagyi GN, et al. Response to neoadjuvant systemic therapy for breast cancer in BRCA mutation carriers and noncarriers: a single-institution experience. J Clin Oncol. 2011;29(28): 3739-46.

31. Gourley C, Michie CO, Roxburgh P, Yap TA, Harden S, Paul J, Ragupathy K, Todd R, Petty R, Reed N, et al. Increased incidence of visceral metastases in Scottish patients with BRCA1/2-defective ovarian Cancer: an extension of the ovarian BRCAness phenotype. J Clin Oncol. 2010;28(15):2505-11.

32. Petrillo M, Marchetti C, De Leo R, Musella A, Capoluongo E, Paris I, Benedetti Panici P, Scambia G, Fagotti A. BRCA mutational status, initial disease presentation, and clinical outcome in high-grade serous advanced ovarian cancer: a multicenter study. Am J Obstet Gynecol. 2017;217(3):334.e1-9.

33. Soslow RA, Han G, Park KJ, Garg K, Olvera N, Spriggs DR, Kauff ND, Levine DA. Morphologic patterns associated with BRCA1 and BRCA2 genotype in ovarian carcinoma. Mod Pathol. 2012;25(4):625-36.

\section{Publisher's Note}

Springer Nature remains neutral with regard to jurisdictional claims in published maps and institutional affiliations.
Ready to submit your research? Choose BMC and benefit from:

- fast, convenient online submission

- thorough peer review by experienced researchers in your field

- rapid publication on acceptance

- support for research data, including large and complex data types

- gold Open Access which fosters wider collaboration and increased citations

- maximum visibility for your research: over $100 \mathrm{M}$ website views per year

At $\mathrm{BMC}$, research is always in progress.

Learn more biomedcentral.com/submissions 